Research Article

\title{
E-Waste awareness among Medical Undergraduates' in a Tertiary Care Teaching Hospital in Delhi, India: A Cross-Sectional Study
}

\author{
Priyanka Sharma', Sneha Kumari', Geeta Yadav ${ }^{3}$, Sanjeet Panesar ${ }^{4}$
}

\author{
${ }^{1}$ Senior Resident, ${ }^{3}$ Professor, Dept. of Community Medicine, VMMC \& Safdarjung Hospital, New Delhi, India. \\ ${ }^{2}$ Assistant Professor, Dept. of Community Medicine, ESI Medical College, Faridabad, Haryana, India. \\ ${ }^{4}$ Assistant Professor, Dept. of Community Medicine, ABVIMS \& RML hospital, New Delhi, India. \\ DOI: https://doi.org/10.24321/2349.2880.201918
}

\section{I $\quad \begin{array}{lllll}\mathbf{N} & \mathbf{F} & \mathbf{O}\end{array}$}

\section{Corresponding Author:}

Sneha Kumari, Dept. of Community Medicine, ESI Medical College, Faridabad, Haryana, India. E-mail Id:

sneharanjan811@gmail.com

Orcid Id:

https://orcid.org/0000-0003-2876-8997

How to cite this article:

Sharma P, Kumari S, Yadav G, Panesar S. E-Waste awareness among Medical Undergraduates' in a Tertiary Care Teaching Hospital in Delhi, India: A Cross-Sectional Study. Ind J Youth Adol Health 2019; 6(4): 19-25.

Date of Submission: 2020-05-05

Date of Acceptance: 2020-05-27

\section{$\begin{array}{llllllll}\mathbf{A} & \mathbf{B} & \mathbf{S} & \mathbf{T} & \mathbf{R} & \mathbf{A} & \mathbf{C} & \mathbf{T}\end{array}$}

Background: Globally, around 44.7 million metric tonnes of e-waste was generated in 2016. India, being the second most populous country in world, generated 2 million metric tonnes of e-waste in 2016. About 5000 metric tonnes of e-waste is imported to India every year. This highlights the need to study awareness about e-waste among the consumers generating it. So, this study was planned with primary objective to assess the knowledge regarding e-waste among medical undergraduate students as they are also the consumers of electronic equipment which constitutes e-waste.

Methodology: The present study was a cross-sectional one, done among 300 medical undergraduate students of a tertiary care hospital and teaching institution in Delhi, India. A pre-tested, semi-structured, self-administered questionnaire was used to gather information from study participants. Descriptive statistical analysis was performed.

Result: More than two-thirds of the $(77.3 \%, 232)$ study participants were aware about concept of e-waste. Out of these 232 students, only about half had adequate knowledge about equipment contributing to e-waste and constituents of e-waste. Most common reason for purchase of new electronics was desire for new technology.

Conclusion: A significant percentage of students (22.7\%) have not even heard of concept of e-waste. Their practices related to e-waste handling were hazardous from both health and environmental aspect. This is an area of concern in this era of growing environmental deterioration. There is a need to study general public awareness also so that appropriate measures can be undertaken.

Keywords: E-Waste, Management, Medical Undergraduates, Hazardous 


\section{Introduction}

Globally, around 44.7 million metric tonnes of e-waste was generated in 2016 which roughly accounts to $6.1 \mathrm{~kg}$ e-waste per inhabitant. ${ }^{1}$ There has been a continuous rising trend of e-waste generation since past few years and this is expected to increase further. ${ }^{1}$ Among all the continents, Asia emerged as the leading generator in 2016, ${ }^{1}$ partly owing to the highest number of inhabitants in this region. Also, $80 \%$ of the generated e-waste remains undocumented worldwide. ${ }^{1}$ One-third of the world's population still remains uncovered from e-waste legislations. ${ }^{1}$ Developing countries import significant quantity of e-waste even though the Basel convention restricts trans-boundary trade of it. ${ }^{2}$

The economy of India is presently the third largest in the world by Purchasing Power Parity (PPP). ${ }^{3}$ This growth has significant economic and social impact as the expeditiously increasing consumption and inusitation rates of electronic products are leading to higher generation of e-waste. India, being the second most populous country in world, generated 2 million metric tonnes of e-waste in $2016 .{ }^{1}$ Although, India and China have their e-waste rules in place, covering Asia's $72 \%$ population by e-waste legislations, but both of them are having rapidly increasing amounts of e-waste which can be attributed to illegal imports and domestic generation. ${ }^{4}$ About 5000 metric tonnes of e-waste is imported to India every year. ${ }^{2}$

Delhi contributes to 9729.2 tonnes of e-waste and is the second largest e-waste generators in India. ${ }^{5}$ Major source of e-waste in India are household electronics and imports. Individual household e-waste contributes to $15 \%$ only, and rest contribution is by manufacturers. ${ }^{5}$

E-waste contains valuable as well as hazardous components. ${ }^{5,6}$ The main constituents found in e-waste are ferrous, nonferrous material, plastic, glass etc. ${ }^{6}$ Hazardous components include heavy metals (lead, mercury, cadmium, chromium), chlorofluorocarbons (CFCs), polychlorinated biphenyls. ${ }^{7}$ Direct contact, inhalation of toxic fumes, accumulation of chemicals in environment leads to detrimental effects on health. ${ }^{7}$ Studies conducted globally proves this fact. ${ }^{8,9,10}$ Processing and recycling activities poses additional risk by production of by-products and injuries. It is hazardous to both health and environment. ${ }^{11}$

Disposed electronics are a considerable category of secondary resource due to their suitability for reuse. This has led to unauthorized e-waste dismantling, recycling, resource recovery which has become a global concern. Large amount of e-waste is handled by the informal collectors who are unaware of proper disposal methods and thus expose themselves and the environment to the harmful effects of e-waste.

There are limited studies regarding India's public awareness of the use of toxic chemicals in these products, government policies regarding their management and proper practices of disposal. An assessment of public awareness at the level of individual is vital to understand public behavior towards e-waste and to understand what is missing from the management strategies. So, this study was planned with primary objective to assess the knowledge regarding e-waste among medical undergraduate students as they are also the consumers of electronic equipment generating e-waste. Their awareness level could give a possible hint to the general public awareness. The secondary objective was to study the practices related to e-waste among the participants.

\section{Materials and Methods}

Study Design and Setting: The present study was a crosssectional one, done in March 2016, among medical undergraduate students of a tertiary care hospital and teaching institution in Delhi, India. The students come from varied backgrounds and states.

Study Population: It comprised of undergraduate students and interns. Inclusion criterion was students using mobile phones, laptops or personal computers (PCs) and those students present at time of study. Exclusion criterion was students in $3^{\text {rd }}$ professional (prof) part-I as data collection was done by a team of students of $3^{\text {rd }}$ prof part 1 . So to eliminate any bias, the students of this prof were excluded from the study.

Sample Size This was calculated using the formula for proportions i.e. $4 \mathrm{PQ} / \mathrm{L}^{2}$. We used the prevalence of knowledge about hazards of e-waste found in previous study as $22 \%$. [12] After taking allowable error as $5 \%$ we got sample size of 275 , which was rounded off to 300 . So a total of 300 students were included.

Study Technique Data collection was done by a team of students of third professional part-I, who were trained by the investigators over a period of 7 days in techniques of interview and data collection. A convenient sampling technique was employed to select the study participants. The students were approached and eligibility was assessed according to above mentioned inclusion criterion. The eligible participants were then informed about the purpose of the study and nature of it. Written informed consent was obtained from each participant who were willing to participate. A semi-structured, self-administered, pretested questionnaire in English was used. A standard questionnaire could not be found, so the authors designed the questionnaire themselves after literature review. This was then peer-reviewed for content and based on their suggestions, necessary modifications were done. The questionnaire was then pilot tested among students of another college, different from our study area. Based on 
pilot testing results, the questionnaire was further modified and finalised and then used for the present study. Data was gathered on socio-demographic information, knowledge regarding e-waste and practices related to e-waste.

\section{Definitions Used in Study}

1. Knowledge about equipment constituting e-wasteParticipants were asked to write 5 electronic equipment constituting e-waste. If all 5 equipment were correctly written, participant was considered to have adequate knowledge, if 3-4 equipment were correctly written, participant was considered to have inadequate knowledge and if less than 3 equipment were written, participant was classified as having no knowledge.

2. Knowledge about constituents of e-waste- E-waste contains lead, iron, cadmium etc. Participants were asked to write 5 constituents of e-waste. If 5 constituents were correctly written, participant was considered to have adequate knowledge, if 3-4 constituents were correctly written, participant was considered to have inadequate knowledge and if less than 3 constituents were written, participant was classified as having no knowledge.

3. Knowledge about role in government policies as consumer- Participants were asked to write 2 roles as consumers. If both the rules were correctly written, student was classified as having adequate knowledge, if one role was written correctly, he/her was classified as having inadequate knowledge and if no role was written correctly, participant was classified as having no knowledge.

Statistical Analysis: Data was entered in MS excel and analysed using SPSS version 21.0. Quantitative data was presented in form of frequencies and percentages for categorical variables. Chi-square/Fischer exact test were employed wherever appropriate for qualitative data analysis. A p value of $<0.05$ was considered as significant.

Ethical Consideration: Permission for conducting the study was obtained from head of the institution. Written informed consent was obtained from each participant. Participants were ensured about confidentiality of data and they were assured that they are free to withdraw from study at any point of time. Privacy and confidentiality of data was assured.

\section{Result}

A total of 300 students were approached and all agreed to participate in study. So, the response rate was $100 \%$. The age range of students was 17 to 25 years.

Maximum number of students $(137,45.7 \%)$ were in age group of 20-22 years. More than half were males (169, $56.3 \%)$. The students of $1^{\text {st }}$ prof of MBBS constituted the highest number $(101,33.7 \%)$ of study participants (Table 1$)$.
Table I.Socio-demographic profile of the study participants $(\mathbf{N}=\mathbf{3 0 0})$

\begin{tabular}{|c|c|c|}
\hline Variable & Frequency & Percentage \\
\hline \multicolumn{3}{|c|}{ Age groups (in completed years) } \\
\hline $17-19$ & 110 & 36.7 \\
\hline $20-22$ & 137 & 45.7 \\
\hline $23-25$ & 53 & 17.6 \\
\hline \multicolumn{3}{|c|}{ Sex } \\
\hline Female & 131 & 43.7 \\
\hline Male & 169 & 56.3 \\
\hline \multicolumn{3}{|c|}{ Year of MBBS } \\
\hline $1^{\text {st }}$ prof & 101 & 33.7 \\
\hline $2^{\text {nd }}$ prof & 77 & 25.7 \\
\hline $3^{\text {rd }}$ prof part-II & 70 & 23.3 \\
\hline Interns & 52 & 17.3 \\
\hline
\end{tabular}

Table 2. Knowledge regarding E-waste among study participants

\begin{tabular}{|c|c|c|}
\hline Variable & Frequency & Percentage \\
\hline \multicolumn{3}{|c|}{ Aware of concept of e-waste (N=300) } \\
\hline Yes & 232 & 77.3 \\
\hline No & 68 & 22.7 \\
\hline
\end{tabular}

Knowledge about equipment constituting e-waste

\begin{tabular}{|c|c|c|}
\hline \multicolumn{3}{|c|}{$(n=232)$} \\
\hline Adequate & 128 & 55.2 \\
\hline Inadequate & 91 & 39.2 \\
\hline No knowledge & 13 & 5.6 \\
\hline \multicolumn{3}{|c|}{ Knowledge about e-waste constituents ( $\mathrm{n}=232$} \\
\hline Adequate & 139 & 59.9 \\
\hline Inadequate & 75 & 32.3 \\
\hline No knowledge & 18 & 7.8 \\
\hline \multicolumn{3}{|c|}{ Consider E-waste hazardous ( $n=232$ ) } \\
\hline Yes & 228 & 98.3 \\
\hline No & 4 & 1.7 \\
\hline
\end{tabular}

Types of e-waste hazards known ( $n=228)$

\begin{tabular}{|c|c|c|}
\hline Environmental & 21 & 9.2 \\
\hline Health & 26 & 11.4 \\
\hline Both & 181 & 79.4 \\
\hline \multicolumn{3}{|c|}{ E-waste collectors heard of : $(\mathbf{n}=\mathbf{2 3 2})$} \\
\hline Only formal & 23 & 9.9 \\
\hline Only informal & 89 & 38.4 \\
\hline Both & 42 & 18.1 \\
\hline None & 78 & 33.6 \\
\hline
\end{tabular}


Aware of government policies related to e-waste ( $n=232)$

\begin{tabular}{|c|c|c|}
\hline Yes & 29 & 12.5 \\
\hline No & 203 & 87.5 \\
\hline
\end{tabular}

Knowledge about role in government policies as consumer $(n=29)$

\begin{tabular}{|c|c|c|}
\hline Inadequate & 6 & 20.7 \\
\hline No knowledge & 23 & 79.3 \\
\hline
\end{tabular}

Source of information about e-waste

\begin{tabular}{|c|c|c|}
\multicolumn{3}{|c|}{$(\mathbf{n = 2 3 2})^{*}$} \\
\hline Internet & 136 & 58.6 \\
\hline Parents & 64 & 27.6 \\
\hline Educational institute & 40 & 17.2 \\
\hline Others** & 32 & 13.8 \\
\hline
\end{tabular}

*Multiple responses present.

** Others include friends, television, print media, radio etc.

None of the study participants, who were aware of government policies related to e-waste, had complete knowledge regarding their role as consumer as prescribed in government policies. When asked if the participants were willing to give their used electronics to e-waste collectors for free, majority $(246,82 \%)$ agreed (Table 2$)$.

The most frequently used electronic was mobile phone for majority of the students $(287,95.7 \%)$. All the students $(300,100 \%)$ have purchased a new electronic in last 5 years. The most common reason for purchase was desire for new technology $(170,56.7 \%)$. About half of the study participants $(155,51.7 \%)$ have kept the older electronics at their home only while $18.4 \%$ (25) have thrown them away in trash (Table 3).
Table 3. Practices related to e-waste among study participants $(\mathbf{N}=\mathbf{3 0 0})$

\begin{tabular}{|c|c|c|}
\hline Variable & Frequency & Percentage \\
\hline \multicolumn{3}{|c|}{ Most frequently used electronics* } \\
\hline Mobile phone & 287 & 95.7 \\
\hline $\begin{array}{l}\text { Laptop/ Personal Computer } \\
\text { (PC) }\end{array}$ & 13 & 4.3 \\
\hline \multicolumn{3}{|c|}{ Mobile phone purchased/ replaced in last 5 years } \\
\hline$\leq 2$ & 112 & 37.3 \\
\hline $3-4$ & 166 & 55.4 \\
\hline$>4$ & 22 & 7.3 \\
\hline
\end{tabular}

PC/ laptop purchased/ replaced in last 5 years

\begin{tabular}{|c|c|c|}
\hline$\leq 1$ & 196 & 65.3 \\
\hline$>1$ & 104 & 34.7 \\
\hline
\end{tabular}

Most common reasons for purchase of new electronics*

\begin{tabular}{|c|c|c|}
\hline Desire for new technology & 170 & 56.7 \\
\hline Loss of function & 80 & 26.6 \\
\hline Physical damage & 39 & 13 \\
\hline Lost/ misplaced & 11 & 3.7 \\
\hline
\end{tabular}

Fate of older electronics*

\begin{tabular}{|c|c|c|}
\hline Kept at home & 155 & 51.7 \\
\hline Trash & 25 & 18.4 \\
\hline $\begin{array}{c}\text { Given/ sold to personal } \\
\text { contact }\end{array}$ & 54 & 18.0 \\
\hline Sold to informal collector & 48 & 16.0 \\
\hline Given to formal collector & 18 & 6.0 \\
\hline
\end{tabular}

*Electronics here refers to mobile phones, personal computers and laptops only.

Table 4.Association between socio-demographic variables and awareness about e-waste among study participants

\begin{tabular}{|c|c|c|c|c|}
\hline Variable & \multicolumn{2}{|c|}{ Aware of e-waste $(\mathrm{N}=300)$} & \multirow{2}{*}{ Total } & \multirow{2}{*}{ p-value } \\
\hline Age groups (in completed years) & Yes & No & & \\
\hline $17-19$ & $93(84.5)$ & $17(15.5)$ & $110(100.0)$ & \multirow{3}{*}{0.076} \\
\hline $20-22$ & $100(73.0)$ & $37(27.0)$ & $137(100.0)$ & \\
\hline $23-25$ & $39(73.6)$ & $14(26.4)$ & $53(100.0)$ & \\
\hline \multicolumn{5}{|c|}{ Sex } \\
\hline Male & $128(75.7)$ & $41(24.3)$ & $169(100.0)$ & \multirow{2}{*}{0.489} \\
\hline Female & $104(79.4)$ & $27(20.6)$ & $131(100.0)$ & \\
\hline \multicolumn{5}{|c|}{ Educational qualification } \\
\hline $1^{\text {st }}$ prof & $86(62.8)$ & $15(37.2)$ & $137(100.0)$ & \multirow{4}{*}{0.080} \\
\hline $2^{\text {nd }}$ prof & $58(75.3)$ & $19(24.7)$ & $77(100.0)$ & \\
\hline $3^{\text {rd }}$ prof part-II & $48(68.6)$ & $22(31.4)$ & $70(100.0)$ & \\
\hline Interns & $40(77.0)$ & $12(23.0)$ & $52(100.0)$ & \\
\hline
\end{tabular}




\begin{tabular}{|c|c|c|c|c|}
\hline \multirow{2}{*}{$\begin{array}{c}\text { Variable } \\
\text { Age groups (in completed years) }\end{array}$} & \multicolumn{2}{|c|}{$\begin{array}{l}\text { Aware of government policies regarding } \\
\text { E-waste }(n=232)\end{array}$} & \multirow[t]{2}{*}{ Total } & \multirow[t]{2}{*}{ p-value } \\
\hline & Yes & No & & \\
\hline $17-19$ & $13(14.0)$ & $80(86.0)$ & $93(100.0)$ & \multirow{3}{*}{0.590} \\
\hline $20-22$ & $10(10.0)$ & $90(90.0)$ & $100(100.0)$ & \\
\hline $23-25$ & $6(15.4)$ & $33(84.6)$ & $39(100.0)$ & \\
\hline \multicolumn{5}{|c|}{ Sex } \\
\hline Male & $14(10.9)$ & $114(89.1)$ & $128(100.0)$ & \multirow{2}{*}{0.425} \\
\hline Female & $15(14.4)$ & $89(85.6)$ & $104(100.0)$ & \\
\hline \multicolumn{5}{|c|}{ Educational qualification } \\
\hline $1^{\text {st }}$ prof & $15(17.4)$ & $71(82.6)$ & $86(100.0)$ & \multirow{4}{*}{$0.142 *$} \\
\hline $2^{\text {nd }}$ prof & $3(5.2)$ & $55(94.8)$ & $58(100.0)$ & \\
\hline $3^{\text {rd }}$ prof part-II & $5(10.4)$ & $43(89.6)$ & 48 (100.0) & \\
\hline Interns & $6(15.0)$ & $34(85.0)$ & 40 (100.0) & \\
\hline
\end{tabular}

*-Fischer exact test.

Table 5.Association between awareness and practices related to e-waste among study participants $(\mathrm{N}=\mathbf{3 0 0})$

\begin{tabular}{|c|c|c|c|c|}
\hline \multirow{2}{*}{$\begin{array}{l}\text { Practices related to e-waste } \\
\text { Mobile purchased/ replaced in last } 5 \text { years }\end{array}$} & \multicolumn{2}{|c|}{ Aware of e-waste } & \multirow{2}{*}{ Total } & \multirow{2}{*}{ p-value } \\
\hline & Yes & No & & \\
\hline$\leq 2$ & $97(86.7)$ & $15(13.3)$ & $112(100.0)$ & \multirow{2}{*}{$0.003^{*}$} \\
\hline$>2$ & $135(71.8)$ & $53(28.2)$ & $188(100.0)$ & \\
\hline \multicolumn{5}{|c|}{ PC/ laptop purchased/ replaced in last 5 years } \\
\hline$\leq 1$ & $145(74.0)$ & $51(26.0)$ & $196(100.0)$ & \multirow{2}{*}{0.061} \\
\hline$>1$ & $87(83.6)$ & $17(16.4)$ & $104(100.0)$ & \\
\hline
\end{tabular}

*- Significant association.

None of the socio-demographic variable was found to be significantly associated with awareness about e-waste among study participants ( $p$-value $>0.05$ ) (Table 4).

A higher percentage of participants who were aware of e-waste concept have purchased/replaced less than or equal to 2 mobile phones in last 5 years than those who were not aware of e-waste concept and the association was statistically significant ( $p$ value $<0.05$ ) (Table 5 ).

\section{Discussion}

Mobile phones and laptops have become a necessity in today's world. Cheap availability, multiple providers, rapid technology advancements all have led to a surge in number of mobile phone users in world and India also. This increased use ultimately translates into generation of equal amounts of E-waste. But sadly, the after-use management of these electronics is not given due importance. To add to this, solar E-waste generated due to solar equipment is also building up constantly. If ignored now, the problem may become catastrophic. So, present study was attempted to assess the awareness of students of a medical teaching institution regarding e-waste which can aid in future public health policy implications.

In present study, more than half of the study participants were males. The age range was $17-25$ years. The findings were comparable to the findings of another study conducted among medical students. ${ }^{13}$ More than three-fourth students were aware or had heard of concept of e-waste. Out of these students, only about half of them knew correctly the equipment constituting e-waste and constituents of e-waste. This is higher than the level of awareness among higher secondary and high school students as found out by Vivek et al. ${ }^{14} \mathrm{E}$-waste is considered hazardous by almost all of the students who had heard of it. This was in contrast to the knowledge of general public. ${ }^{12,15}$ Low knowledge regarding equipment constituting e-waste will automatically lead to improper management and disposal. Such equipment should come with a hazard symbol or mention of e-waste label for consumers so that they can be disposed of accordingly in accordance with guidelines. Almost one-third of the students had never heard about 
any e-waste collector. Only $9.9 \%$ had heard of formal e-waste collectors which was similar to the findings of study conducted among general public. ${ }^{15}$ With purchase of a new electronic, an information booklet is provided by the manufacturer which usually mentions the method of disposal of that electronic item. But due to lack of awareness, very few people read and comply with those instructions. There is need for further research into this arena to look for better strategies for consumer awareness regarding not only about use but also disposal of the electronic equipment.

Adding to this, a mere $12.5 \%$ of students out of 232 were aware of government policies regarding e-waste in India. Rest were unaware of it. Even who were aware of government policies, more than three-fourth of them were completely clueless about their roles as defined in those policies. This highlights the glaring deficiencies in awareness about e-waste and its management among students. It can then be rightly predicted that general public would be having a lower awareness level which was evident from findings of another study. ${ }^{15}$ This makes the problem even much larger.

In present study, only $17.2 \%$ students out of 232 students, who were aware about e-waste, had acquired this knowledge from their educational institutions. Educational institutions can play a major role in sensitising students to the issue of e-waste, its hazards and its management. Inclusion of e-waste in educational curriculum at school and college level can make a big difference. Awareness campaigns highlighting this issue can be planned and executed. World environment day which is celebrated on $5^{\text {th }}$ June can be used as an opportunity to run such campaigns. E-day which is celebrated in New Zealand to create awareness about e-waste can be a good example to learn from.

All the participants in present study had purchased a mobile phone/ laptop/ PC in last 5 years. This was similar to another study in which $99.4 \%$ students were using their handsets for less than 5 years. ${ }^{13}$ The most common reason for purchase of new electronic equipment was desire for new technology, a finding similar to other study by Mittal A et al among medical undergraduates and study by Shah A et al among general public. ${ }^{13,15}$

A higher percentage of students in present study had kept older electronics at home $(51.7 \%)$ as compared to another studies. ${ }^{13,15}$ But this was comparable to another study done in Nigeria among households. ${ }^{12}$ About one-fifth students had thrown away their older electronics in trash which was also higher as compared to previous study. ${ }^{13}$ But this was much lower compared to study by Okoye et al. ${ }^{12}$ This is a dangerous practice as e-waste thrown away in trash is likely to be handled by rag pickers which includes children also. They might suffer injuries due to the toxic elements present in these equipments. Also, it leads to environmental pollution due to leaching of chemicals into water, soil and air if the hazardous materials present in them come in contact with the environment.

Although the percentage of students who know about any system of collection of e-waste was higher, the students who were actually giving their old electronics to any such system is much lower. The reason for such wide gap between knowledge and practice could be attributed to the lack of knowledge about the government policies and their role as consumers. A qualitative research is required to identify the other possible reasons associated with these practices.

\section{Strengths}

This study is amongst the few studies conducted in North India among medical undergraduate students to assess their awareness about e-waste. Students from varied age group and different professional years of MBBS were included. Scientific method of sample size calculation was used.

\section{Limitations}

The study can't be generalised to general population as it was conducted among medical students. Selection bias could be present as we used a non-probability sampling technique.

\section{Conclusion}

The knowledge of students regarding e-waste and government policies was not satisfactory. A significant percentage of students have not even heard of concept of e-waste. Their practices related to e-waste handling were hazardous from both health and environmental aspect. This is an area of concern in this era of growing environmental deterioration. The students are amongst the important e-waste generators as the desire for new technology and e-learning methods compel them to rely highly on electronic equipment like computers and mobile phones.

\section{Recommendation}

There is a need to study general public awareness also so that appropriate awareness programmes can be planned for consumers and public health policies can be formulated in regard to e-waste. Qualitative studies are also required to understand the behavioural patterns associated with use and purchase of electronic equipment. Manufacturers should inform their customers regarding safe disposal practices of electronic equipment. Policies and rules should be translated into Acts and they should be strictly implemented. Violation of consumers' responsibility should be strictly looked upon and appropriate legal actions should be taken. Consumers should be made aware about e-waste, its hazards and their role in its management. 


\section{Acknowledgement}

Authors would like to acknowledge the study participants for their time and response. We would also like to acknowledge team of students who helped in data collection.

\section{Funding}

This research did not receive any specific grant from funding agencies in the public, commercial, or not-for-profit sectors.

\section{Declarations of Interest: None}

\section{Conflict of Interest: None}

\section{References}

1. Balde CP, Forti V, Gray V, Kuehr R, Stegmann P. The global e-waste monitor 2017. Quantities, flows and resources. United Nations University and International telecommunications union. Geneva, Bonn, Vienna November 2017. Available from https://www.itu.int/ en/ITU-D/Climate-Change/Documents/GEM\%202017/ Global-E-waste\%20Monitor\%202017\%20.pdf. [Last accessed on 04/06/2019].

2. Khattar V, Kaur J, Chaturvedi A, Arora A. E-waste assessment in India: Specific focus on Delhi, A quantitative understanding of generation, disposal and recycling of electronic waste 2007 Nov. BIRD. GTZ.

3. The world bank. World Development Indicators database. GDP ranking, PPP based. World Bank, 2019 January. Available from https://databank.worldbank. org/data/download/GDP_PPP.pdf. [Last accessed on 04/06/2019].

4. Widmer R, Krapf HO, Khetriwal DS, Schnellmann M, Boni H. Global perceptives on E-waste. Environmental Impact Assessment Review 2005; 25: 436-458.

5. Kumar B. E-Waste - Environment and Human Health Hazards and Management. IRSEE. NAIR. Vadodara, India. Available from http://www.nair.indianrailways.gov.in/ uploads/files/1410168855632-PNM\%20E-wast\%20 mgt_Abhivyakti.pdf. [Last accessed on 04/06/2019].

6. Wath SB, Dutt PS, Chakrabarti T. E-waste scenario in India, it's management and implications. Environ Monit Assess 2011; 172: 249-262.

7. WHO. Electronic waste. Children's environmental health. Environmental risks. WHO. Geneva, Switzerland. Available from http://www.who.int/ceh/risks/ewaste/ en/. [Last accessed on 04/06/2019].

8. Tyagi A, Chatterjee S. Liquid Crystal Display. Environment \& Technology 2013; 1(7): 110-123.

9. Kiddee $\mathrm{P}, \mathrm{Naidu} \mathrm{R}$, Wong $\mathrm{MH}$. Electronic waste management approaches: an overview. Waste Manag 2013; 33(5): 1237-1250.

10. Soo VK, Featherston C, Doolan M. E-waste Assessment in Malaysia. Re-engineering Manuf Sustain SE - 64 2013:389-95. DOI- https://doi.org/10.1007/978-981-
4451-48-2_64. Available from https://link.springer. com/chapter/10.1007\%2F978-981-4451-48-2_64 [Last accessed on 04/06/2019].

11. Annamalai J. Occupational health hazards related to informal recycling of Ewaste in India: An overview. Indian J Occup Environ Med 2015; 19(1): 61-65.

12. Okoye, Odoh C. Assessment of the Level of Awareness of E-Waste Management and Concern for the Environment amongst the Populace in Onitsha, Southeastern Nigeria. Journal of Environmental Protection 2014; 5(2): 120 134.

13. Anuj M, Rajasekar VD, Krishnagopal L. A Study to Assess Economic Burden and Practice of Cell Phone Disposal among Medical Students. J Clin Diagn Res 2013; 7(4): 657-660.

14. Licy CD, Vivek R, Saritha K, Anies TK, Josphina CT. Awareness, Attitude and Practice of School Students towards Household Waste Management. Journal of Environment 2013; 2(6): 147-150 .

15. Shah A, Dhakal T, Pandey T, Shah NK. Assessment of public awareness regarding e waste hazards and management strategies, Ahmedabad, India, 2014. Independent Study Project (ISP) Collection. 1820. DOI- https:// digitalcollections.sit.edu/isp_collection/1820. Available from https://digitalcollections.sit.edu/cgi/viewcontent. cgi?referer=\&httpsredir=1\&article $=2832$ \& context=isp_ collection. [Last accessed on 04/06/2019]. 